\title{
CHARACTERISTIC VALUE OF THE RANDOM FIRE LOAD DENSITY Probability-based specification depending on the way how the building compartment is used
}

\author{
Mariusz Maslak \\ Cracow University of Technology, Faculty of Civil Engineering, Cracow, Poland
}

\begin{abstract}
The algorithm that allows to specify the characteristic value of the random fire load density, depending on the way how the considered building compartment is used, is presented and discussed in detail. The proposed computational procedure is based on a probabilistic approach, the alternative in relation to the traditional methodology according to which the results obtained from the inventory of such a compartment are a basis for the evaluation. It is assumed that the sought value is estimated as the upper quantile of a Gumbel probability distribution which is set at an appropriate level of the probability of its up-crossing. The formal model described in the paper is referred to the two selected and qualitatively different design techniques which are used in practice. The first one is based on the recommendations contained in the Eurocode EN 1991-1-2, whereas the second - on the rules specified in the standard NFPA 557.
\end{abstract}

Keywords: fire load density, characteristic value, building compartment, quantile, Gumbel probability distribution.

\section{INTRODUCTION}

It is common knowledge that the fire load $Q$ can be treated as a quantitative measure of the heat energy which could be released in building compartment as a result of a fully developed fire occurrence, by the combustion of the combustible contents of such a compartment together with all combustible parts of the building itself. For this reason, its value is usually classified as one of the two basic quantities determining the development and the intensity of the anticipated fire (the second one is the opening factor $O$ which describes the ventilation capabilities of a fire zone). However, in design practice the specification of a total value of this energy is not as important as the unambiguous determination how the potential fire load is arranged inside the considered building compartment. It should be verified whether it is uniformly distributed or rather grouped in local maxima of a significant value. Therefore, the fire load density $q_{f}=Q / A_{f}\left[\mathrm{MJ} / \mathrm{m}^{2}\right]$ is in general introduced to the fire safety analysis, quantifying the energy dissipated per unit floor area $A_{f}$. Let us note that in some practical applications the other fire load density $\left.q_{t}=Q / A_{t} \mid \mathrm{MJ} / \mathrm{m}^{2}\right\rfloor$ may be determined, relating to the unit area of all the partitions surrounding the building compartment (i.e. not only of its floor but also of its walls and ceiling). Such density is usually denoted by the subscript " $t$ ", which means "the total area", but it is essential that it is quantitatively different than the value previously mentioned. Nevertheless, it is always true that $q_{f}=q_{t}\left(A_{t} / A_{f}\right)$. The classic approach to determine the value $q_{f}$ (or $q_{t}$ ) corresponding to the specific building compartment is to perform inside the detailed inventory through which all materials potentially possible to burn will be identified. This procedure is undoubtedly very laborious and anyway of little practical value because the way of the use of the typical building compartment can frequently change resulting in the uselessness of the assessment previously performed. On the other hand, the estimation made in this way seems to be the most precise but it is justified only for the considered specific case selected for verification. As a consequence, the value of a fire load density obtained from the inventory in building compartment should be treated as the nominal value, understood in 
further analysis as a fully deterministic parameter. An alternative approach, which is based on the use of the statistical analysis, seems to be the methodology being significantly more practical because that takes into account the randomness of the fire load density identified for building compartments which are used in a similar way. In fact, it is true but provided that its representative value, acceptable by the building users and denoted as the characteristic one, is calibrated in a trustworthy manner. The aim of this paper is to present and to discuss in detail the two design algorithms relating to such a calibration procedure which are used in practice, and finally to show that they are qualitatively different one to the other.

\section{DETERMINATION OF THE NOMINAL VALUE OF A FIRE LOAD DENSITY BASED ON THE DETAILED INVENTORY OF THE CONSIDERED BUILDING COMPARTMENT}

To unambiguously determine the sought value of a fire load density $q_{f}$ (or $q_{t}$ ) characterising the considered building compartment the value of a potential fire load $Q$ identified for such a compartment should be estimated earlier on the basis of the following formula:

$$
Q=\sum_{i=1}^{n} m_{i} H_{u, e f f, i}[\mathrm{MJ}]
$$

where $m_{i}[\mathrm{~kg}]$ is the mass of the $i$-th combustible material which has been identified in the considered building compartment while $H_{u, e f f, i}=\chi_{\mathrm{i}} H_{u, i}$ is the effective net calorific value describing the energy efficiency resulting from the combustion of unit of mass of such a material. The factor $\chi_{\mathrm{i}} \leq 1$ reduces the value $H_{u, i}[\mathrm{MJ} / \mathrm{kg}]$ measured for the examined material during the laboratory calorimetric test being performed under the ideal combustion conditions. Let us note that in engineering practice this reducing factor is frequently neglected in the calculations (for example in the standard EN 1991-1-2) which may be justified by the difficulty in unambiguously determination of its value. Nevertheless, the simplification of this type leads to the unnecessary overestimation of the value being assessed, although it should be noted that its evaluation is on the safe side. There are many practical techniques of the collecting of these input data which are necessary for the effective application of the Eq. (1). The most commonly used are as follows: the direct weighing method; the indirect weighing method according to which the volume of the individual materials is estimated first, then the density of such the materials is selected and finally the weight of each of these materials is calculated; the real estate website review where the estimation of the fire load is performed based on the photos or even based on the films taken before in the considered building compartment; and the questionnaire method with the assessment based on the data compiled by the building users and next reported to the evaluator in a specialised questionnaire (Maslak, 2014). In the standard NFPA 557 it is recommended to separate during the evaluation of a fire load being specific for the considered building compartment the movable fire load usually interpreted as the contents fire load (for example furnishing, books, carpets, curtains etc.) and the fixed fire load which is constituted by the combustible structural members as well as by the cladding materials used to finish floors, walls, ceiling etc.

\section{THE CONCEPT OF THE STATISTICAL ANALYSIS OF THE RANDOM FIRE LOAD DENSITY IN BUILDING COMPARTMENTS USED IN A SIMILAR WAY.}

The use of the statistical analysis in the calibration procedure of the specific value of a random fire load density which could be treated as the representative one for the considered building compartment requires an unequivocal grouping of all identifiable building compartments into the homogeneous populations specified depending on the way in which they are used. Currently in the professional literature many of such divisions is recommended for various applications, however only the two of them are included in the standards commonly used in engineering practice. The first one is given in the Annex E to the standard EN 1991-1-2. It is differentiated as follows: homes and 
flats, hospital rooms, libraries, offices, classrooms, shops and shopping centres, cinemas and theatres as well as the facilities intended for communication (for example railway and bus stations). The qualitatively different groups are recommended to be used in the standard NFPA 557. They are as follows: office or business occupancies, religious properties, eating or drinking establishments, educational buildings, facilities that care for the sick, stores or mercantile buildings, places where people sleep other than homes, other public assembly buildings. As one can see, in the latter case it does not stand out the homes and the flats as the separate research group which probably results from the specific fire safety regulations in the USA. On the other hand, the corresponding generalisation and grouping should be associated with the combustible materials being identifiable in the considered building compartment. In general, they are assigned to the three (rarely to the four) basic groups such as: paper and wood (usually combined into a one group as the cellulosebased materials), plastics and textiles. The percentage share of the materials belonging to each of the groups of materials which have been specified above in a total fire load value estimated separately for the particular types of the building compartments, as they have been previously identified, has been studied by many authors (for example: Culver, 1978; Kumar and Rao, 1997). It is particularly interesting that in recent years the share of the plastics is significantly increasing whereas the paper-based materials are used increasingly less (Zalok and Eduful, 2013).

The multiple well-justified calculation of the value of the fire load density performed for many cases of the building compartment classified to the one specific type of its use (for example based on the inventory of such a compartment, as it has been shown in the previous part of this paper) provides for this group a statistically homogeneous set of results which allows to treat this quantity as the random variable. As a consequence, the appropriate histogram relating to this random variable may be constructed, and finally the empirical mean value of such the variable estimated as its expected value as well as its empirical standard deviation may be calculated. After detailed analysis of all histograms obtained in practice for that particular types of building compartment which have been identified previously it turned out that they are not symmetrical with respect to the expected value of the random fire load density. This was because the occurrence of the value lower than the average was reported more frequently than the occurrence of the value higher than this one, thus the probability of its random realisation was significantly higher. For this reason not the empirical mean value seems to be the essential in the fire safety analysis but the empirical dominant value, i.e. this one occurring most frequently, even though it is considerably lower than the expected value of a random fire load density obtained empirically.

\section{SPECIFICATION OF THE CHARACTERISTIC VALUE OF THE FIRE LOAD DENSITY AS THE UPPER QUANTILE OF A GUMBEL PROBABILITY DISTRIBUTION}

The problem how to select the a priori known probability distribution such that its fit to the histogram obtained empirically was as good as possible was discussed in many works. Some of the authors (Kumar and Rao, 1997; Bwalya et al., 2004) recommended the log-normal probability distribution as that being accurate for practical use in this field. On the other hand, the other authors reported that the Weibull (Korpela and Kushner, 2000) as well as the Gumbel (Ramachandran, 1982) probability distributions seem to be significantly more accurate because of their non-zero skewness. Finally, both in the EN 1991-1-2 and in the standard NFPA 557 the Gumbel probability distribution was chosen to characterise the random fire load density. Furthermore, its representative characteristic value $q_{f k}$ was assumed to be estimate as the upper quantile of such a distribution with the probability of the up-crossing of such a level equal to $p$. In order to specify the characteristic value $q_{f k}$ the empirical mean value $\overline{q_{f}}$ as well as the empirical standard deviation $\sigma_{q f}$ should be taken directly from the histogram. They are calculated as follows:

$$
\overline{q_{f}}=\overline{q_{f, f}}+\overline{q_{f, c}} \quad \text { and } \quad \sigma_{q f}=\sqrt{\sigma_{q f, f}^{2}+\sigma_{q f, c}^{2}}
$$


where the random fire load density $q_{f, f}$ is associated with the fixed fire load while $q_{f, c}$ with the contents (movable) fire load. The next step is the conversion of these empirical parameters on the corresponding parameters relating to the Gumbel probability distribution, particularly the modal value $\tilde{q}_{f}$ (in other words the value for which the probability of its occurrence is the highest in the reference period adopted to the analysis) as well as the Gumbel standard deviation $u_{q f}$. By using the classical method of the probabilistic moments one can obtain:

$$
\tilde{q}_{f}=\overline{q_{f}}-0,577 \frac{\sqrt{6}}{\pi} \sigma_{q f}=\overline{q_{f}}-0,45 \sigma_{q f} \quad \text { and } \quad u_{q f}=\frac{\sqrt{6}}{\pi} \sigma_{q f}=0,78 \sigma_{q f}
$$

where the coefficient 0,577 is the so-called Euler constant. The sought quantile value, i.e. the characteristic value $q_{f k}$, is now calculated directly from the equation:

$$
q_{f k}=\tilde{q}_{f}-u_{q f} \ln [-\ln (p)]=\overline{q_{f}}-\frac{\sqrt{6}}{\pi} \sigma_{q f}\{0,577+\ln [-\ln (p)]\}
$$

The essential in the analysis presented above is the decision about such the level of the probability $p$ which could be the maximum acceptable probability of the up-crossing of the characteristic value $q_{f k}$ by the random value $q_{f}$. For example, if the design approach proposed in the EN 1991-1-2 is chosen for practical use then in the Annex E in such a standard one can find that the characteristic value $q_{f k}$ is such a specific level of the random fire load density $q_{f}$ for which it is guaranteed that it will not be exceeded in random realisation with the probability $q=1-p=0,8$. This definition is an equivalent to the conclusion that the probability $p$ is set to be equal to $p=0,2$. Such an arbitrary determination of the maximum acceptable level of the probability $p$ raises doubts because it seems that this value should be specified more precisely, on the basis of the detailed risk analysis both of the fire initiate and of its flashover. Let $T_{r}$ denotes the return period relating to the characteristic value $q_{f k}$, which is the average time-period, given in years, between the subsequent random events manifesting themselves by the exceedance of this level. Then the following occurs:

$$
p=P\left(q_{f}>q_{f k}\right)=1-P\left(q_{f} \leq q_{f k}\right)=1-q=1-\frac{1}{T_{r}}
$$

Let us discuss in detail the alternative approach leading to the specification of the characteristic value $q_{f k}$ which is proposed in the standard NFPA 557. In this procedure the representative value $q_{f k}$ is specified based on the decision about the maximum acceptable level of the risk $R_{S}$. Such the specific risk value is interpreted here as the maximum permissible number of failures calculated per one year of the building use. If such a failure is understood as the occurrence in the considered building compartment of a structurally significant fire resulting in the total or only in the partial degradation of the load-bearing structure then the following occurs:

$$
T_{r}=\frac{f_{S S}}{R_{s}}=\frac{f_{s} A_{f}}{R_{s}}
$$

where $f_{s s}$ is the estimated frequency of the occurrence of such the structurally significant fires in a homogeneous group containing the specific building compartments which are used in a similar way. It is expressed in the number of such the fires per one year of the building use. It is obvious that the analogous frequency $f_{s}$ is in this equation measured additionally per one square meter of the considered building compartment. The combination of the Eqs. (3), (4) and (5) leads to the evaluation of the characteristic value $q_{f k}$ given in the standard NFPA 557 by the following formula: 


$$
q_{f k}=\overline{q_{f}}-\frac{\sqrt{6}}{\pi} \sigma_{q f}\left\{0,577+\ln \left[-\ln \left(1-\frac{R_{s}}{f_{s s}^{*}}\right)\right]\right\}
$$

in which the maximum acceptable value of the risk $R_{S}$ is set at the level $10^{-6}$ of the catastrophic fire occurring per one year of the building use. The particular frequencies $f_{s S}$ are in such a standard assessed empirically for each type of the considered building compartment previously identified. These are as follows:

- for offices and business occupancies - 6 fires per million $\mathrm{m}^{2}$ per one year,

- for religious properties -6 fires per million $\mathrm{m}^{2}$ per one year,

- for eating and drinking establishments -81 fires per million $\mathrm{m}^{2}$ per one year,

- for educational buildings -10 fires per million $\mathrm{m}^{2}$ per one year,

- for facilities that care for the sick - 16 fires per million $\mathrm{m}^{2}$ per one year,

- for stores and mercantile buildings - 16 fires per million $\mathrm{m}^{2}$ per one year,

- for places where people sleep other than homes - 43 fires per million $\mathrm{m}^{2}$ per one year,

- for other public assembly buildings - 10 fires per million $\mathrm{m}^{2}$ per one year.

The values presented above should be corrected by the factor $\chi \leq 1$, to the values $f_{s s}^{*}=\chi f_{s s}$, before they are introduced to the Eq. (7). The reduction ratio depends on the type of the load-bearing structure as well as on the manner of its protection against fire. Detailed values of the factors $\chi$ are specified in the standard NFPA 557 in the appropriate tables which are assigned to the particular types of the considered building compartments.

\section{CONCLUDING REMARKS}

In the presented paper two alternative procedures resulting in the specification of the characteristic value of a random fire load density are discussed and compared one to the other. They are qualitatively different despite the fact that in both cases the considered random variable is characterised by the same type of a probability distribution. The main difference results, however, from a slightly different interpretation of what is meant by such a characteristic value which is calibrated in each procedure being analysed. On the one hand, in the approach recommended in the standard EN 1991-1-2 the value $q_{f k}$ is understood as a such specific level of a random fire load density $q_{f}$ which may be legally up-crossed with the probability $p=0,2$, assumed previously to be independent on the type of the considered building compartment and fixed at a constant level. On the other hand, the use of the approach proposed in the standard NFPA 557 leads to the conclusion that the probability $p$ is not fixed uniformly at the same level for all the types of a building compartment but it is tailored to the level of the risk depending on the type of a loadbearing structure as well as on the manner of its protection against fire. Let us note that in both cases the characteristic value $q_{f k}$ is determined by the empirical mean value $\overline{q_{f}}$ as well as by the empirical standard deviation $\sigma_{q f}$. In fact, they are explicitly specified in the standard EN 1991-1-2 as those they were obtained from a detailed statistical analysis. However, such the statement does not seem to be quite true because it is not fully unambiguous. It is a well-known fact that the values obtained empirically generally depend on the manner in which they were collected. This means that the method of conducting of the inventory in the considered building compartment has a strong influence on the obtained results. Nevertheless, it is commonly accepted that the most trustworthy is in this field the combination of the traditional inventory with the direct weighing of all the combustible materials identified in building compartment. It was also shown that the basic 
parameters of the typical Gumbel probability distributions characterising the random fire load density have significantly changed over the last forty years i.e., since the suitable observations are carried out. Compared to the results reported from the studies performed in early seventies of the last century (Holm and Oksanen, 1970 cited by Hietaniemi and Mikkola, 2010) the values of a fire load density measured nowadays are significantly higher if they are relate to the analogous types of building compartments. Moreover, the corresponding empirical standard deviation is also increased. To sum up, the current standards give some estimates of random values of a fire load density being specific for the considered type of building compartment. In general, they stem from the research conducted several years ago. For this reason the calibration of the characteristic value $q_{f k}$ should be associated with an additional although the non-binding assumption that in relation to the present time these estimates may already be a bit outdated, and therefore understated.

\section{REFERENCES}

Bwalya A.C., Sultan M., Benichou N., 2004. A pilot survey of fire loads in Canadian homes. Research Report No 159. National Research Council, Ottawa, Canada.

Culver C., 1978. Characteristics of fire loads in office buildings. Journal of Fire Technology, 14(1), p. 5160.

EN 1991-1-2, Eurocode 1: Action on structures. Part 1-2: General actions - Actions on structures exposed to fire.

Hietaniemi J., Mikkola E., 2010. Design fires for fire safety engineering, VTT Working Paper 139, VTT, Finland.

Holm C., Oksanen P., 1970. Palokuorman määrä kerrostalojen asuinhuoneistoissa. Palontorjuntatekniikka, 2, p. 1-4.

Korpela K., Kushner J., 2000. Fire loads in office buildings. In: $3^{\text {rd }}$ International Conference on Performance-Based Codes and Fire Safety Design Methods, June 15-17, 2000, Lund, Sweden.

Kumar S., Rao C.V.S.K., 1997. Fire loads in office buildings. Journal of Structural Engineering, 123 (3), p. 365-368.

Maslak M., 2014. Probabilistic interpretation of the characteristic value specified for random fire load density in building compartment (in Polish), Materiaty Budowlane, 10, p. 90-92.

NFPA 557, 2012. Standard for determination of fire loads for use in structural fire protection design, National Fire Protection Association, Quincy, MA, USA.

Ramachandran G., 1982. Properties of extreme order statistics and application in fire protection and insurance problems. Fire Safety Journal, 5 (1), p. 59-76.

Zalok E., Eduful J., 2013. Assessment of fuel load survey methodologies and its impact on fire load data, Fire Safety Journal, 62, p. 299-310. 